\title{
The Effects of 12-week Instrumental Pilates on Isokinetic Muscular Function and Body Composition in College Women
}

\author{
Hyo-Jin Kim, Ji-Yeon Kim, Yue-Zhu Zhou and Changsun Kim* \\ Department of Physical Education, Dongduk Women's University, Seoul, Korea
}

\section{Article Info \\ Received 2021.07.08. \\ Revised 2021.09.13. \\ Accepted 2021.09.28. \\ Correspondence* \\ Changsun Kim \\ chang@dongduk.ac.kr}

\section{Key Words}

instrumental pilates exercise, healthy college women,

isokinetic muscle strength,

muscle mass,

body composition

이 논문은 2020년도 동덕여자대학교

학술연구비 지원에 의하여 수행된 것임.

본 논문은 김효진의 박사학위 논문을

일부 수정 보완한 것임.
PURPOSE The aim of this study was to investigate the effects of 12 -week instrumental pilates exercise on isokinetic muscle function and body composition of healthy college women. METHODS Twenty-four college women (aged 21.6 $\pm 1.3 y$ rs) were recruited to the study. The participants were divided into two groups, as the instrumental pilates group (IPG, $n=12$ ) and the control group ( $C G, n=12)$. The springboard pilates exercise was conducted 3 times a week for 40 60 minutes during 12 weeks. RESULTS There was significant interaction effects in the right knee and left - right elbow extensor muscles $\left(60^{\circ} / \mathrm{sec}\right)$ and left knee flexor and right elbow extensor - flexor muscles $\left(180^{\circ} / \mathrm{sec}\right)(p<.05, p<.01)$. There was no significant interaction effects in the muscle mass of the total body, trunk, arms, and legs (NS) and also in the serum growth hormone, insulin-like growth factor-I and 25(OH)Vitamin D (NS). Serum creatine kinase was significantly increased $(p<.05)$. There was also no significant interaction effects in weight, body fat, serum total cholesterol, triglycerides, low \& high-density lipoprotein cholesterol (NS). CONCLUSIONS These results suggest that although prolonged instrumental pilates exercise of healthy college women might be improving isokinetic muscle function, there is no increasing effect of muscle mass.

\section{서론}

필라테스(Pilates)는 코어의 안정성을 중심으로 전신 근력 운동을 통해 신체 균형을 바로 잡아주는 운동이다(Pilates \& Miller, 1945). 오래전 부터 장기간의 필라테스 운동은 강한 근수축의 반복 운동을 통하여 정 적 및 동적 밸런스 향상(Fitt et al., 1993), 요추 통증 경감(Geweniger, 2002), 신체 유연성(Latey, 2002), 코어 강화(Segal et al., 2004), 척 추 기립근의 안정화(Sekendiz et al., 2007), 자세 교정(Herrington \& Davies, 2005; Siler, 2000) 등 다양한 효과가 있는 것으로 알려져 있 다. 119편의 논문을 대상으로 체계적 문헌고찰 실시한 연구(Wells et. al., 2012)에서도 필라테스는 근력과 코어 안정성, 유연성, 근육 조절, 자 세 그리고 호흡에 초점을 맞춘 운동이라 정의하고 있다.

한편, 필라테스는 코어 운동을 중심으로 하는 매트 필라테스와 기구의 저항을 이용하여 전신 근력운동을 할 수 있는 기구 필라테스로 나뉘어 진다(Anderson \& Spector, 2005). 매트 필라테스는 매트 위에서 써클 링(Circle ring), 저항밴드, 스몰볼(Small ball), 쿠션(Cushion) 등의 소 도구를 이용한 코어발달 중심의 운동으로 동시에 다수가 운동할 수 있는 장점이 있어 폭 넓게 보급되고 있다. 기구 필라테스는 캐딜락(Cadillac), 스프링보드(Springboard), 리포머(Reformer), 체어(Chair), 래더바렐 (Ladder Barrel)등을 이용하므로 매트 필라테스에 비하여 동시 이용 인
원에 있어 제한적이지만, 코어강화와 함께 팔과 다리의 근력을 강화시킬 수 있는 운동이다(Oliveira et al., 2015). 기구 필라테스의 경우 각 기구 들의 다양한 저항에 대항하여 운동을 실시하므로, 매트 위에서 소도구만 을 이용하는 매트 필라테스와 효과면에서 차이가 나타난다. 매트 필라테 스의 경우, 여대생을 대상으로 10 주 간 주 3 회의 실시 후 악력, 배근력, 윗몸 일으키기 등 근력 및 근지구력 지표가 증가했다는 보고(Hwang et al., 2012)와 만 45세 60세의 폐경기 여성 총 21명을 대상으로 8주간 요부안정화 필라테스 운동을 실시한 결과 최대근력과 평균근력을 향상 시켰다는 보고(Lee et al., 2017)가 있지만, 매트 필라테스는 전신 근력 운동의 효과에 있어서는 다소 미비하다고 보고(Liemohn et al., 2005; Eyal, 2010)되고 있기도 하다. 또한 여대생을 대상으로 장기간의 기구 필라테스 운동을 실시하여 등속성 근력에 미치는 영향을 평가하고 근육 량의 변화를 검토한 연구는 부족한 실정이다.

또한, 장기적인 매트 필라테스는 신체 조성인 체지방과 체지방률에 긍 정적인 효과(Hong et al., 2006; Kim et al., 2009)와 긍정적이지 않다 는 연구(Lee et al., 2006; Choi \& Kim, 2006)가 혼재하고 있다. 최근 8 주간의 비대면 홈 필라테스 운동이 출산 후 여성의 체지방량, BMI, 내장 지방, 피하지방 두께, 복부 둘레, 엉덩이 둘레 등을 유의하게 감소시킨다 는 보고(Hyun \& Cho, 2021)와 같이 팬데믹 이후의 체지방 개선을 위한 비대면 운동 방법으로의 가능성도 시사되는 필라테스이지만, 장기간의 
기구 필라테스 운동에 따른 신체조성에 미치는 영향을 검토한 연구 또한 부족한 실정이다. 신체 조성에 있어서 체지방은 혈중 콜레스테롤 등의 혈 중지질 요소들과 높은 관련성이 있으며(Katzmarzyk et al., 2001), 근 육량은 성장호르몬 등의 근육 성장인자들의 영향을 받는다(Kraemer et al., 1993).

따라서, 본 연구에서는 장기간의 기구 필라테스 운동이 등속성 근력을 포함한 근기능 및 근육량 등의 신체조성, 혈중 지질대사, 근육 성장인자 등에 미치는 효과를 검토하기 위하여 건강한 여자대학생 24 명을 대상으 로 1 일 60 분, 주 3 회, 12 주 간의 스프링보드 필라테스 운동 부하 실험을 실시하였다.

\section{연구방법}

\section{연구대상}

본 연구의 대상자는 사전 질문에 의하여 특별한 질환이 없으며, 최근 6 개월간 체계적인 운동경험이 없는 24 명의 여대생들을 선정하였으며, 무작위로 기구 필라테스 운동그룹(Instrumental Pilates Group; IPG, $\mathrm{n}=12$ )과 대조그룹(Control Group; CG, n=12)으로 나누어서 12주 간 의 기구 필라테스 전과 후의 근기능 및 신체조성의 변화를 비교하였다. 연구대상자들의 신체적인 특성은 〈Table 1)과 같다.

\section{기구 필라테스 운동 부하}

필라테스 스프링보드 운동 집단(IPG)에게 12주간, 주3회, 1 회 40 60분 의 필라테스 스프링보드 운동을 진행하였다. 운동 강도는 개인의 신체 적인 특성을 고려하여서 운동 자각도(Rating Of Perceived Exertion; $\mathrm{RPE}$ )를 이용하여 1 4주(RPE: 9 12), 5 8주(RPE: 10 14), 9 12주 (RPE: 11 16)동안 점진적으로 강도를 증가 시켰다. 전반적인 필라테스 스프링보드 운동 프로그램 구성은 〈Table 2〉와 같다. 준비운동과 정리 운동은 정해진 시간 동안 충분히 수행 하였으며, 본 운동은 총 12 종목을 실시하였으며, 반복횟수는 각 종목별로 주관적 강도에 따라 4 12회로 점증적으로 증가시켰으며, 세트 수 또한 1 세트에서 2세트까지 점증적으 로 증가시켜 적용하였다.

Table 1. The characteristics of subjects

\begin{tabular}{cccc}
\hline Variables & $\mathrm{CG}(\mathrm{n}=12)$ & $\mathrm{IPG}(\mathrm{n}=12)$ & $p$ \\
\hline Age $(\mathrm{yrs})$ & $22.75 \pm 1.42$ & $22.50 \pm 1.24$ & .651 \\
Height $(\mathrm{cm})$ & $161.28 \pm 5.05$ & $159.18 \pm 4.17$ & .281 \\
Weight $(\mathrm{kg})$ & $54.33 \pm 4.01$ & $54.68 \pm 4.50$ & .846 \\
BMI $\left(\mathrm{kg} / \mathrm{m}^{2}\right)$ & $20.92 \pm 1.69$ & $21.54 \pm 1.16$ & .301 \\
\hline
\end{tabular}

Values are mean \pm SD. BMI, body mass index; CG; control group, IPG; instrumental pilates group.

Table 2. Instrumental pilates exercise program

\begin{tabular}{|c|c|c|c|c|c|c|c|c|c|c|}
\hline & \multirow{3}{*}{ Program } & \multicolumn{9}{|c|}{ Duration(Weeks) } \\
\hline & & \multicolumn{3}{|c|}{$1 \sim 4$} & \multicolumn{3}{|c|}{$5 \sim 8$} & \multicolumn{3}{|c|}{$9 \sim 12$} \\
\hline & & RPE & Rep. & Set & RPE & Rep. & Set & RPE & Rep. & Set \\
\hline \multirow{3}{*}{$\begin{array}{l}\text { Warm up } \\
\text { (5min) }\end{array}$} & - $\quad$ Self massage & 9 & $10 \sim 12$ & 2 & 9 & $10 \sim 12$ & 2 & 9 & $10 \sim 12$ & 2 \\
\hline & - $\quad$ Breathing & 9 & $10 \sim 12$ & 2 & 9 & $10 \sim 12$ & 2 & 9 & $10 \sim 12$ & 2 \\
\hline & - Spine articulation & $9 \sim 10$ & $6 \sim 8$ & 2 & $10 \sim 11$ & $8 \sim 10$ & 2 & $10 \sim 12$ & 10 & 2 \\
\hline \multirow{12}{*}{$\begin{array}{l}\text { Instrumental Pilates } \\
\text { Exercise } \\
(30 \sim 50 \mathrm{~min})\end{array}$} & - Roll down & $9 \sim 10$ & 6 & 1 & $10 \sim 11$ & $6 \sim 8$ & 2 & $10 \sim 12$ & $8 \sim 10$ & 2 \\
\hline & - $\quad$ Side sit ups & $9 \sim 10$ & 6 & 1 & $11 \sim 12$ & $6 \sim 8$ & 1 & $11 \sim 13$ & $8 \sim 10$ & 2 \\
\hline & - $\quad$ Kneeling & $9 \sim 11$ & 8 & 1 & $10 \sim 11$ & 12 & $1 \sim 2$ & $11 \sim 14$ & $8 \sim 10$ & 2 \\
\hline & - Knee pulls & $9 \sim 11$ & 5 & 1 & $10 \sim 11$ & 8 & $1 \sim 2$ & $11 \sim 14$ & 8 & 2 \\
\hline & - $\quad$ Lying leg spring & $9 \sim 10$ & 5 & 1 & $10 \sim 11$ & $6 \sim 8$ & $1 \sim 2$ & $11 \sim 14$ & 10 & 2 \\
\hline & - Lying arm series & $9 \sim 12$ & 1 & 1 & $10 \sim 11$ & 2 & $1 \sim 2$ & $11 \sim 14$ & 1 & 2 \\
\hline & - Abdominal & $9 \sim 11$ & 5 & 1 & $10 \sim 11$ & 6 & $1 \sim 2$ & $11 \sim 14$ & 8 & 2 \\
\hline & - Swan & $9 \sim 11$ & 6 & 1 & $10 \sim 12$ & $6 \sim 8$ & $1 \sim 2$ & $11 \sim 14$ & $8 \sim 10$ & 2 \\
\hline & - $\quad$ Teaser & $9 \sim 10$ & 3 & 1 & $10 \sim 11$ & $6 \sim 8$ & $1 \sim 2$ & $11 \sim 14$ & $8 \sim 10$ & 2 \\
\hline & - Kneeling arm series & $9 \sim 10$ & 8 & 1 & $10 \sim 11$ & 8 & 1 & $11 \sim 14$ & 8 & 1 \\
\hline & - $\quad$ Standing arm series & $9 \sim 12$ & 5 & 1 & $10 \sim 13$ & $6 \sim 8$ & $1 \sim 2$ & $11 \sim 14$ & $8 \sim 10$ & 2 \\
\hline & - Plyometric & $9 \sim 10$ & 8 & 1 & $10 \sim 12$ & 10 & 2 & $12 \sim 16$ & 10 & 2 \\
\hline \multirow{2}{*}{$\begin{array}{l}\text { Cool down } \\
\text { (5min) }\end{array}$} & - $\quad$ Stretch & $9 \sim 12$ & $10 \sim 15$ & 2 & $9 \sim 12$ & $10 \sim 15$ & 2 & $9 \sim 13$ & $10 \sim 15$ & 2 \\
\hline & - Massage & 6 & 1 & 1 & 6 & 1 & 1 & 6 & 1 & 2 \\
\hline
\end{tabular}

40 60 min/day, 3 times/week, during 12 weeks

RPE, rating of perceived exertion; Rep., repeat. 


\section{측정 항목 및 방법}

\section{1. 등속성 근력 측정}

등속성기능은 Isokinetic Dynamometer Cybex(Norm system $770, \mathrm{USA})$ 를 이용하여 측정하였다. 측정부위는 무릎관절과 팔꿈치관절 로 근력 측정을 위해서 각속도 $60 \% \mathrm{sec}$ 에서는 3 회, 총 일량과 근지구력 측정을 위해서 각속도 $180 \% / \mathrm{sec}$ 에서는 26회 조건에서 실시하였으며, 각각 굴근 및 신근을 측정하였다. 측정 항목은 체중당 최대근력(peak torque \% $\mathrm{BW}$ ), 근지구력(muscular endurance)을 측정하였다. 근지구 력은 처음 시작과 끝에서 나타난 토크(Torque)의 감소 정도를 측정하여 비율(ratio, \%)로 나타냈다. 검사 전에 부상방지를 위해 충분한 스트레 칭을 하였고, 대상자가 편안한 상태를 유지할 수 있도록 안정을 취하였 으며, 측정 시에는 상, 하체의 움직임을 방지하기 위해 고정 밸트를 착용 하였다.

\section{2. 근육량 및 혈중 근육 성장인자 측정}

근육량은 이중에너지 방사선 측정법(Dual Energy X-ray Absorptiometry; DEXA, Hologic Inc, USA)으로 전신을 측정한 후, 전
신을 포함하여 몸통과 팔, 다리의 세부적인 근육량을 평가하였으며, 체 지방량 및 체지방률도 산출하였다. 혈중 근육 성장인자로는 혈청 중의 성장호르몬(Growth Hormon; GH) 및 인슐린 유사 성장인자(Insulin like Growth Factor-I; IGF-I), 비타민 D(25(OH)Vitamin D), 크레아 틴 키나아제(Creatinine Kinase; $\mathrm{CK}$ )를 전문혈액 분석 회사인 S사에 의뢰하여 분석하였다. 이를 위하여 12 시간 이상 금식 후 대상자들의 상 완주정맥에서 1 회용 주사기로 약 $4 \mathrm{ml}$ 의 혈액을 채혈하였다. 채혈한 혈 액은 약 $3,500 \mathrm{rpm}$ 에서 10 분간 원심 분리하여 혈청을 분리하여 $-80^{\circ} \mathrm{C}$ 냉동고에 보관하였다.

\section{3. 체지방 및 혈중 지질대사 마커 측정}

체지방량 및 체지방률은 근육량과 함께 이중에너지 방사선 측정법 (DEXA, Hologic Inc, US)으로 측정하였으며, 혈중 지질대사 마커로 $\mathrm{TC}, \mathrm{TG}$ 와 HDL-C는 동일하게 혈액 분석 회사에 의뢰하여 분석하였 고, $\mathrm{LDL}-\mathrm{C}$ 는 다음의 계산식을 이용하여 산출하였다.

$$
\text { LDL-C }=\text { TC }-[H D L-C-(T G / 5)]
$$

Table 3. Effects of 12 -week instrumental pilates on isokinetic muscle strength of knee \& elbow peak torque $\left(60^{\circ} / \mathrm{sec}\right)$

\begin{tabular}{|c|c|c|c|c|c|c|c|c|}
\hline & Varia & & Group & Before & After & Source & $F$ & $p$ \\
\hline \multirow{12}{*}{ Knee } & \multirow{6}{*}{ Right } & \multirow{3}{*}{ Ex $(\% B W)$} & CG & $213.08 \pm 35.15$ & $203.25 \pm 26.68$ & group & .005 & .443 \\
\hline & & & & & & time & .129 & .809 \\
\hline & & & IPG & $196.58 \pm 23.13$ & $204.50 \pm 26.49$ & $\mathrm{~g} \times \mathrm{t}$ & 6.379 & .023 \\
\hline & & \multirow{3}{*}{$\mathrm{Fl}(\% \mathrm{BW})$} & $\mathrm{CG}$ & $101.17 \pm 23.66$ & $99.58 \pm 19.35$ & group & .597 & .456 \\
\hline & & & & & & time & .010 & .920 \\
\hline & & & IPG & $93.58 \pm 19.83$ & $95.83 \pm 19.74$ & $g \times t$ & .559 & .470 \\
\hline & \multirow{6}{*}{ Left } & \multirow{3}{*}{$\mathrm{Ex}(\% \mathrm{BW})$} & CG & $202.67 \pm 37.55$ & $196.58 \pm 25.82$ & group & .195 & .667 \\
\hline & & & & & & time & .024 & .880 \\
\hline & & & IPG & $191.17 \pm 23.21$ & $198.67 \pm 23.92$ & $g \times t$ & 4.198 & .065 \\
\hline & & \multirow{3}{*}{$\mathrm{Fl}(\% \mathrm{BW})$} & CG & $95.25 \pm 22.10$ & $96.08 \pm 20.09$ & group & .121 & .735 \\
\hline & & & & & & time & 3.541 & .087 \\
\hline & & & IPG & $89.42 \pm 17.89$ & $96.08 \pm 23.69$ & $g \times t$ & 1.628 & .228 \\
\hline \multirow{12}{*}{ Elbow } & \multirow{6}{*}{ Right } & \multirow{3}{*}{$\mathrm{Ex}(\% \mathrm{BW})$} & CG & $36.00 \pm 9.40$ & $33.25 \pm 7.06$ & group & .005 & .944 \\
\hline & & & & & & time & .129 & .726 \\
\hline & & & IPG & $32.25 \pm 7.25$ & $36.50 \pm 11.64$ & $g \times t$ & 6.379 & .028 \\
\hline & & \multirow{3}{*}{$\mathrm{Fl}(\% \mathrm{BW})$} & $\mathrm{CG}$ & $30.75 \pm 8.40$ & $31.25 \pm 7.06$ & group & .001 & .972 \\
\hline & & & & & & time & 1.247 & .288 \\
\hline & & & IPG & $29.75 \pm 6.06$ & $32.00 \pm 8.80$ & $g \times t$ & .420 & .530 \\
\hline & \multirow{6}{*}{ Left } & \multirow{3}{*}{ Ex $(\% \mathrm{BW})$} & $\mathrm{CG}$ & $32.50 \pm 6.63$ & $29.75 \pm 6.20$ & group & .562 & .469 \\
\hline & & & & & & time & 7.301 & .021 \\
\hline & & & IPG & $27.75 \pm 6.02$ & $36.33 \pm 10.59 * *$ & $g \times t$ & 13.569 & .004 \\
\hline & & \multirow{3}{*}{$\mathrm{Fl}(\% \mathrm{BW})$} & $\mathrm{CG}$ & $31.75 \pm 4.52$ & $30.25 \pm 6.33$ & group & .038 & .849 \\
\hline & & & & & & time & .050 & .828 \\
\hline & & & IPG & $29.50 \pm 6.11$ & $31.50 \pm 9.00$ & $g \times t$ & 2.736 & .126 \\
\hline
\end{tabular}

Values are mean $\pm \mathrm{SD}$; Ex, extensor; Fl, flexor; $\mathrm{CG}$, control group; IPG, instrumental pilates group; $F$-values from two way repeated ANOVA; **: $\mathrm{p}<.01$ vs before by paired t-test(post-hoc test). 


\section{통계 처리}

측정한 모든 변인들의 값은 Windows SPSS 23.0 statistics package(SPSS Inc., Chicago, IL, USA)를 이용하여 분석하였다. 두 집 단의 차이 비교를 위하여 평균과 표준편차를 제시하였다. 두 집단의 필 라테스 스프링보드 운동 효과 비교를 위하여 이원변량반복분산분석 (two-way repeated measure ANOVA)을 실시하였으며 집단, 시기, 집 단 $x$ 시기에 따른(2 by 2) 평균값의 차이를 분석하였다. ANOVA검사 후 유의한 차이가 있는 경우, 사후검사로 시기간은 paired t-test, 집단간에 는 independent t-test를 실시하였다. 통계적 유의수준 $(\alpha)$ 은 $\alpha=.05$ 로 설정하였다.

\section{연구결과}

등속성 근기능

\section{1. 등속성 최대 근력}

12 주 기구 필라테스가 무릎과 팔꿈치관절의 굽힘근과 폄근의 등속성 최대 근력(peak torque, $60 \% \mathrm{sec}$ )에 미치는 효과를 〈Table 3〉에 나타냈 다. 좌·우측 무릎 및 팔꿈치 굽힘근에서는 통계적으로 유의한 변화를 확 인할 수 없었지만, 우측 무릎관절 및 좌· 우측 팔꿈치관절 폄근에서 그룹 $x$ 시기 간에서 유의한 상호작용효과가 나타났으며( $\mathrm{p}<.05, \mathrm{p}<.01), \mathrm{CG}$ 에서는 감소하는 경향을 나타낸 반면, IPG에서 각각 약 $4.0 \%, 13.2 \%$, $30.9 \%$ 증가하는 것으로 나타났다.

\section{2. 등속성 최대 근지구력}

등속성 최대 근지구력(endurance muscle strength, $180 \%$ sec)은 좌 측 무릎 폄근 및 우측 팔꿈치폄근과 굽힘근에서 그룹 $\times$ 시기 간에서 유의 한 상호작용효과가 나타났으며(p〈.05, p〈.01), CG에서는 감소하는 경 향을 나타낸 반면, IPG에서 각각 약 $4.8 \%, 3.5 \%, 6.6 \%$ 증가하는 것으로 나타났다(Table 4).

Table 4. Effects of 12-week instrumental pilates on isokinetic muscle strength of knee \& elbow endurance strength $(180 \% \mathrm{sec}$

\begin{tabular}{|c|c|c|c|c|c|c|c|c|}
\hline & Vari & & Group & Before & After & Source & $F$ & $p$ \\
\hline \multirow{12}{*}{ Knee } & \multirow{6}{*}{ Right } & \multirow{3}{*}{$\begin{array}{c}\text { Ex-En } \\
\operatorname{ratio}(\%)\end{array}$} & CG & $72.58 \pm 3.23$ & $73.42 \pm 3.03$ & group & 1.194 & .298 \\
\hline & & & \multirow{2}{*}{ IPG } & \multirow[b]{2}{*}{$72.83 \pm 3.90$} & \multirow{2}{*}{$75.00 \pm 3.67$} & time & 1.597 & .232 \\
\hline & & & & & & $g \times t$ & .633 & .443 \\
\hline & & \multirow{3}{*}{$\begin{array}{c}\text { Fl-En } \\
\operatorname{ratio}(\%)\end{array}$} & CG & $77.17 \pm 10.16$ & $70.83 \pm 9.39$ & group & .898 & .364 \\
\hline & & & \multirow{2}{*}{ IPG } & & \multirow{2}{*}{$71.50 \pm 8.85$} & time & 3.594 & .085 \\
\hline & & & & & & $g \times t$ & 3.507 & .088 \\
\hline & \multirow{6}{*}{ Left } & \multirow{3}{*}{$\begin{array}{c}\text { Ex-En } \\
\text { ratio(\%) }\end{array}$} & CG & $73.50 \pm 5.49$ & $73.42 \pm 3.55$ & group & 699 & .421 \\
\hline & & & \multirow{2}{*}{ IPG } & \multirow[b]{2}{*}{$73.17 \pm 4.04$} & \multirow[b]{2}{*}{$76.67 \pm 5.84 * *$} & time & 2.709 & .128 \\
\hline & & & & & & $g \times t$ & 6.256 & .029 \\
\hline & & \multirow{3}{*}{$\begin{array}{c}\text { Fl-En } \\
\operatorname{ratio}(\%)\end{array}$} & CG & $75.42 \pm 8.96$ & $71.00 \pm 8.61$ & group & .121 & .735 \\
\hline & & & \multirow{2}{*}{ IPG } & \multirow{2}{*}{$71.00 \pm 7.76$} & \multirow{2}{*}{$73.17 \pm 10.63$} & time & .452 & .515 \\
\hline & & & & & & $g \times t$ & 3.159 & .103 \\
\hline \multirow{12}{*}{ Elbow } & \multirow{6}{*}{ Right } & \multirow{3}{*}{$\begin{array}{c}\text { Ex-En } \\
\operatorname{ratio}(\%)\end{array}$} & \multirow{2}{*}{$\mathrm{CG}$} & \multirow[t]{2}{*}{$85.50 \pm 12.70$} & \multirow[t]{2}{*}{$75.17 \pm 11.90^{*}$} & group & .002 & .963 \\
\hline & & & & & & time & 1.643 & .226 \\
\hline & & & IPG & $79.17 \pm 11.81$ & $81.92 \pm 13.55$ & $g \times t$ & 6.199 & .030 \\
\hline & & \multirow{3}{*}{$\begin{array}{c}\text { Fl-En } \\
\operatorname{ratio}(\%)\end{array}$} & \multirow[t]{2}{*}{ CG } & \multirow[t]{2}{*}{$85.42 \pm 13.56$} & \multirow[t]{2}{*}{$78.67 \pm 13.08$} & group & .263 & .618 \\
\hline & & & & & & time & .055 & .819 \\
\hline & & & IPG & $81.42 \pm 12.35$ & $86.75 \pm 7.15$ & $g \times t$ & 12.589 & .005 \\
\hline & & & CG & $75.33 \pm 10.82$ & $74.33 \pm 14.85$ & group & 1.315 & .276 \\
\hline & & EX-En & & & & time & 2.585 & .136 \\
\hline & Jo & & IPG & $74.75 \pm 14.51$ & $85.58 \pm 14.20$ & $g \times t$ & 2.982 & .112 \\
\hline & & & CG & $82.67 \pm 12.05$ & $79.83 \pm 8.65$ & group & .318 & .584 \\
\hline & & Гl-El & & & & time & .001 & .974 \\
\hline & & iando $(70)$ & IPG & $81.67 \pm 7.78$ & $84.67 \pm 6.07$ & $g \times t$ & 1.517 & .244 \\
\hline
\end{tabular}

Values are mean $\pm \mathrm{SD}$; Ex, extensor; Fl, flexor; En, endurance strength; $\mathrm{CG}$, control group; IPG, instrumental pilates group; $F$-values from two way repeated ANOVA; *: p<.05, **: $\mathrm{p}<.01$ vs before by paired t-test(post-hoc test). 


\section{근육량 및 근육 성장인자}

\section{1. 근육량}

제지방량을 포함하여 전신 및 몸통, 팔, 다리의 근육량에서 그룹 $\times$ 시 기의 상호작용효과는 나타나지 않았다(Table 5).

\section{2. 혈중 근육대사 지표}

성장호르몬(Growth Hormon; GH) 및 인슐린 유사 성장인자(Insulin like Growth Factor-I; IGF-I), 25(OH)Vitamin D 에서는 그룹x시 기의 상호작용효과는 나타나지 않았다. 크레아틴 키나제(Creatinine Kinase; $\mathrm{CK}$ )에서는 그룹 $\times$ 시기 간에서 유의한 상호작용효과가 나타났 다(p〈.05, p<.01)(Table 5).

\section{체지방 및 지질대사}

\section{1. 체지방}

체중을 포함하여 체지방량 및 체지방률에서는 그룹 $\times$ 시기의 상호작용 효과는 나타나지 않았다(Table 6).

\section{2. 혈중 지질대사 지표}

총콜레스테롤(Total Cholesterol, T-C) 및 중성지방(Triglyceride, $\mathrm{TG}$ ), 저밀도 지단백 콜레스테롤(Low Density Lipoprotein Cholesterol, LDL-C), 고밀도 지단백 콜레스테롤(High Density Lipoprotein Cholesterol, HDL-C)에서 그룹× 시기의 상호작용효과는 나타나지 않았다(Table 6).

Table 5. Effects of 12-week instrumental pilates on body muscle mass by DEXA and serum muscle growth factors

\begin{tabular}{|c|c|c|c|c|c|c|}
\hline Variables & Group & Before & After & Source & $F$ & $p$ \\
\hline \multirow{3}{*}{ Lean body mass (kg) } & CG & $36.68 \pm 2.34$ & $36.10 \pm 2.48$ & group & .699 & .421 \\
\hline & \multirow[b]{2}{*}{ IPG } & \multirow[b]{2}{*}{$35.31 \pm 2.65$} & \multirow[b]{2}{*}{$35.73 \pm 2.76$} & time & .208 & .658 \\
\hline & & & & $g \times t$ & 1.435 & .256 \\
\hline \multirow{3}{*}{ Body muscle mass (kg) } & CG & $35.06 \pm 2.43$ & $34.83 \pm 2.63$ & group & .840 & .379 \\
\hline & \multirow[b]{2}{*}{ IPG } & \multirow[b]{2}{*}{$33.73 \pm 2.70$} & \multirow[b]{2}{*}{$33.44 \pm 2.42$} & time & 5.978 & .033 \\
\hline & & & & $g \times t$ & .567 & .467 \\
\hline \multirow{3}{*}{ Trunk muscle mass (kg) } & CG & $16.86 \pm 1.45$ & $16.65 \pm 1.63$ & group & 1.791 & .208 \\
\hline & \multirow[b]{2}{*}{ IPG } & \multirow[b]{2}{*}{$16.07 \pm 1.67$} & \multirow[b]{2}{*}{$15.94 \pm 1.41$} & time & 1.641 & .227 \\
\hline & & & & $\mathrm{g} \times \mathrm{t}$ & .085 & .776 \\
\hline \multirow{3}{*}{ Arms muscle mass (kg) } & CG & $3.20 \pm 0.27$ & $3.18 \pm 0.32$ & group & .216 & .651 \\
\hline & \multirow[b]{2}{*}{ IPG } & \multirow[b]{2}{*}{$3.12 \pm 0.36$} & \multirow{2}{*}{$3.15 \pm 0.37$} & time & .037 & .851 \\
\hline & & & & $\mathrm{g} \times \mathrm{t}$ & 1.395 & .262 \\
\hline \multirow{3}{*}{ Legs muscle mass (kg) } & CG & $11.70 \pm 0.89$ & $11.70 \pm 0.75$ & group & 5.173 & .044 \\
\hline & \multirow[b]{2}{*}{ IPG } & \multirow[b]{2}{*}{$11.29 \pm 0.73$} & \multirow[b]{2}{*}{$11.10 \pm 0.83$} & time & 1.373 & .266 \\
\hline & & & & $\mathrm{g} \times \mathrm{t}$ & 1.610 & .231 \\
\hline \multirow{3}{*}{$\mathrm{GH}(\mathrm{ng} / \mathrm{mL})$} & CG & $4.84 \pm 2.70$ & $3.10 \pm 3.47$ & group & .802 & .390 \\
\hline & \multirow{2}{*}{ IPG } & \multirow[b]{2}{*}{$3.27 \pm 3.25$} & \multirow[b]{2}{*}{$4.55 \pm 2.36$} & time & .086 & .775 \\
\hline & & & & $g \times t$ & 2.237 & .163 \\
\hline \multirow{3}{*}{ IGF-I (ng/mL) } & CG & $290.58 \pm 89.42$ & $298.25 \pm 84.11$ & group & .019 & .894 \\
\hline & \multirow[b]{2}{*}{ IPG } & \multirow[b]{2}{*}{$280.92 \pm 90.50$} & \multirow[b]{2}{*}{$298.42 \pm 91.35$} & time & .549 & .474 \\
\hline & & & & $g \times t$ & .078 & .786 \\
\hline \multirow{3}{*}{ 25(OH)Vitamin D (ng/mL) } & CG & $10.52 \pm 2.38$ & $12.97 \pm 2.82$ & group & 11.267 & .006 \\
\hline & \multirow[b]{2}{*}{ IPG } & \multirow[b]{2}{*}{$12.77 \pm 2.40$} & \multirow[b]{2}{*}{$17.34 \pm 2.65$} & time & 25.090 & .000 \\
\hline & & & & $g \times t$ & 4.878 & .051 \\
\hline & CG & $117.58 \pm 96.33$ & $65.42 \pm 24.80$ & group & .014 & .909 \\
\hline $\mathrm{CK}(\mathrm{U} / \mathrm{L})$ & & & & time & .936 & .354 \\
\hline & IPG & $74.42 \pm 28.16$ & $104.42 \pm 41.10^{*}$ & $g \times t$ & 5.807 & .035 \\
\hline
\end{tabular}

Values are mean \pm SD; DEXA, dual energy x-ray absorptiometry; CG, control group; IPG; instrumental pilates group; HGH, human growth hormone; IGF-I, insulin-like growth factor-I; CK, creatinine kinase. *: $\mathrm{p}<.05$ vs before by paired t-test(post-hoc test). 
Table 6. Effects of 12-week instrumental pilates on body weight, fat and blood lipids profiles

\begin{tabular}{|c|c|c|c|c|c|c|}
\hline Variables & Group & Before & After & Source & $F$ & $p$ \\
\hline \multirow{3}{*}{ Weight (kg) } & CG & $54.33 \pm 4.01$ & $54.44 \pm 4.71$ & group & .011 & .918 \\
\hline & \multirow{2}{*}{ IPG } & \multirow[b]{2}{*}{$54.68 \pm 4.50$} & \multirow[b]{2}{*}{$53.72 \pm 4.38$} & time & 1.011 & .336 \\
\hline & & & & $g \times t$ & 3.241 & .099 \\
\hline \multirow{3}{*}{ Body fat mass (kg) } & CG & $16.72 \pm 4.66$ & $17.09 \pm 4.50$ & group & .608 & .452 \\
\hline & \multirow{2}{*}{ IPG } & \multirow[b]{2}{*}{$18.71 \pm 4.30$} & \multirow[b]{2}{*}{$18.12 \pm 3.98$} & time & .051 & .826 \\
\hline & & & & $\mathrm{g} \times \mathrm{t}$ & 1.725 & .216 \\
\hline \multirow{3}{*}{ Body fat (\%) } & CG & $30.93 \pm 6.70$ & $31.83 \pm 6.16$ & group & .920 & .358 \\
\hline & \multirow{2}{*}{ IPG } & \multirow[b]{2}{*}{$33.58 \pm 5.44$} & \multirow[b]{2}{*}{$34.27 \pm 5.78$} & time & .088 & .773 \\
\hline & & & & $g \times t$ & 2.359 & .153 \\
\hline \multirow{3}{*}{$\mathrm{T}-\mathrm{C}(\mathrm{mg} / \mathrm{dl})$} & \multirow{2}{*}{ CG } & \multirow[t]{2}{*}{$186.25 \pm 30.63$} & \multirow[t]{2}{*}{$180.33 \pm 39.16$} & group & .090 & .770 \\
\hline & & & & time & .010 & .921 \\
\hline & IPG & 184.9237 .34 & $189.67 \pm 35.56$ & $g \times t$ & .756 & .403 \\
\hline \multirow{3}{*}{$\mathrm{TG}(\mathrm{mg} / \mathrm{dl})$} & CG & $76.58 \pm 38.34$ & $72.83 \pm 31.94$ & group & 1.628 & .228 \\
\hline & \multirow[b]{2}{*}{ IPG } & \multirow[b]{2}{*}{$77.58 \pm 32.19$} & \multirow[b]{2}{*}{$93.33 \pm 47.54$} & time & 1.384 & .264 \\
\hline & & & & $g \times t$ & 2.397 & .150 \\
\hline \multirow{3}{*}{ LDL-C (mg/dl) } & CG & $96.52 \pm 20.29$ & $97.43 \pm 30.92$ & group & .428 & .526 \\
\hline & \multirow{2}{*}{ IPG } & \multirow[b]{2}{*}{$98.73 \pm 32.56$} & \multirow[b]{2}{*}{$104.42 \pm 26.48$} & time & .309 & .589 \\
\hline & & & & $g \times t$ & .182 & .678 \\
\hline \multirow{3}{*}{ HDL-C (mg/dl) } & $\mathrm{CG}$ & $74.42 \pm 13.09$ & $68.33 \pm 17.12$ & group & .139 & .717 \\
\hline & \multirow{2}{*}{ IPG } & \multirow{2}{*}{$70.67 \pm 17.41$} & \multirow{2}{*}{$66.58 \pm 16.85$} & time & 3.472 & .089 \\
\hline & & & & $g \times t$ & .143 & .713 \\
\hline
\end{tabular}

Values are mean $\pm \mathrm{SD}$; CG, control group; IPG, instrumental pilates group; T-C, total cholesterol; TG, triglyceride; LDL-C, low density lipoprotein cholesterol; HDL-C, high density lipoprotein cholesterol.

\section{논의}

본 연구에서는 장기간의 기구 필라테스 운동이 근기능과 신체조성에 미 치는 효과를 검토하기 위하여, 건강한 여자대학생 24 명을 두 집단으로 나 누어 기구 필라테스 집단(IPG)에게 1 일 60 분, 주 3 회, 12 주 간의 필라테 스 스프링보드 운동 부하 실험을 실시하여 대조집단(CG)과 비교하였다.

그 결과 기구 필라테스 집단의 우측 무릎관절 및 좌우측 팔꿈치관절 폄근의 등속성 최대 근력 $\left(60^{\circ} / \mathrm{sec}\right)$ 에서 유의하게 증가 하였으며, 좌측 무릎 폄근 및 우측 팔꿈치폄근과 굽힘근의 등속성 최대 근지구력(180\% $\mathrm{sec})$ 에서도 유의하게 증가 하는 것이 밝혀졌다. 필라테스는 반복적인 동 작과 호흡 조절을 통해 요부의 안정성에 기여하는 근육들을 활성화시켜 근력 향상에 효과적(Phrompaet et al., 2011)이라 알려져 있다. 실제 18 세 30세 건강한 여성 11명을 대상으로 3가지의 전통적인 매트 필라 테스 동작시의 근활성도를 검토한 결과 $15 \%$ $61 \% \mathrm{MVIC}$ 의 근활성도를 나타낸다고 보고되고 있다(Menacho et al., 2010). 또한 여대생을 대상 으로 매트 필라테스 운동을 1 일 50 분, 주 2 회, 12 주 간 실시한 연구에서 는 근력이 증가했다고 보고하고 있으며(Yoon et al., 2007), 여대생을 대상으로 필라테스와 댄스스포츠를 1 일 80 분, 주 2회, 14 주 간 실시한 연구에서도 배근력이 증가했다고 보고되고 있다(Park \& Lee, 2009). 그 러나 여대생들을 대상으로 매트 필라테스 운동을 1 일 80분, 주 2 회, 12 주 간 실시한 연구에서는 근력에는 영향을 미치지 못했다는 보고도 있
다(Park et al., 2011). 이들 연구에서는 코어 발달을 중심으로 하는 운 동으로 매트 필라테스를 실시하고 있어, 스프링과 같은 저항을 이용하 는 기구 필라테스에 비교하여 근력 발달에는 제한적이라 할 수 있으며 (Anderson \& Spector, 2005), 근력 측정으로도 악력, 배근력등을 측정 하고 있어 근력 변화를 검토하기에는 제한점이 있었다.

본 연구에서는 근력 변화를 판단하기 위하여 등속성 장비로 팔꿉과 무 릎 관절의 굽힘과 폄근의 최대 등속성 근력과 근지구력을 평가하였다. 등속성 운동은 관절 가동 범위에 있어 일정한 속도로 근 수축이 발생되 도록 하는 운동으로(Knapik et al., 1983), 부하는 일정하게 작용하는 반면 움직이는 근육이 발휘하는 장력은 관절의 가동범위 각도에 따라 서 다르기 때문에 측정에 있어서 신뢰도와 타당도가 높다고 보고되었다 (Hislop \& Perrine, 1967). 이처럼 등속성 장비를 이용하여 근력을 측정 한 연구에서는 필라테스 운동의 근력향상에 있어서의 긍정적 효과가 보 고되고 있다. 여대생을 대상으로 탄력밴드를 이용한 필라테스를 1 일 50 분, 주 3 회, 12 주 간 실시한 연구에서도 등속성 하지 근력의 증가를 보고 하고 있다(Hwang et al., 2016). 탄력밴드는 저항성운동이 가능한 소도 구로 본 연구에서 채택한 스프링보드와 유사하다고 할 수 있다. 실제로 캐딜락, 리포머, 체어와 바렐 등의 다양한 기구 필라테스를 복합적으로 적용한 실험에서도 무릎 관절 등속성 근력에서 기구 필라테스 운동그룹 이 대조그룹에 비하여 굽힘근 뿐만 아니라 폄근에서도 유의하게 증가하 는 것이 보고되고 있다(Oliveira et al., 2016; Oliveira et al., 2017). 이 
처럼 본 연구에서 실시한 스프링보드 기구 필라테스는 매트 필라테스와 대조적으로 스프링의 부하를 이용하여 무릎과 팔꿈치 관절에 다양한 운 동을 실시하였고, 저항부하가 작용하여 등속성 근력발달에 효과적이었 다고 판단된다.

한편 이러한 근력 발달에 근육량의 영향을 검토하기 위하여 비교적 정교하다고 알려진 $\mathrm{DEXA}$ 를 이용하여 전신 및 몸통, 팔, 다리의 근육량 을 측정하였다. 그 결과 두 집단 간의 유의한 차이는 나타나지 않았다. Hwang 등(2012)의 여대생을 대상으로 매트 필라테스 운동을 1일 50 분, 주 3 회, 10 주 간 실시한 연구에서도 근육량에는 유의미한 차이가 없 었다고 보고하고 있어 본 연구의 결과를 뒷받침 해준다. 따라서 등속성 근력 및 근지구력의 향상은 근육의 양적 향상 보다는 근기능적 향상에 의한 것으로 추측되어진다. 이를 확인하기 위한 추가 연구가 필요하다 고 판단된다.

또한 혈중 근육 성장인자인 성장호르몬과 인슐린 유사 성장인자-I, 25(OH)Vitamin D에서도 유의한 차이는 발견하지 못했다. 그러나 크레 아틴 키나아제(CK)에서는 유의하게 증가하는 것으로 밝혀졌다. 이는 여 대생을 대상으로 매트 필라테스 운동을 1일 70 80분, 주 3회, 8주 간 실 시한 연구(Kim et al., 2014a)에서 CK가 유의하게 증가하여 근육 대사 에 영향을 미쳤다는 결과와 유사하다. $\mathrm{CK}$ 는 근 세포에서 일어나는 대사 작용을 간접적으로 알 수 있는 지표로, 신체 운동에 의해 활성이 증가함 으로써 신체 및 근 손상 정도를 나타내는 지표이다(Yoon, 1998). 고령 자를 대상으로 실시한 일회성 매트 필라테스 운동 후에도 약 1.4 배 정도 CK가 증가하는 것으로 밝혀져 있다(Kim et al., 2014b). 본 연구의 기 구 필라테스 운동이 근육 대사에 영향을 주고 있었음을 반추할 수 있는 결과라고 판단된다. 또한, 비타민 D에서는 유의한 상호작용을 나타내지 는 못했지만 증가하는 경향을 나타냈다(p=.051). 추후 기구 필라테스와 비타민 $\mathrm{D}$ 의 관련성에 대해서도 연구가 필요하다고 판단된다.

한편 본 연구 결과 체중을 포함하여 체지방량 및 체지방률에서 상호작 용효과는 나타나지 않았으며, 혈중 지질대사 지표인 총콜레스테롤 및 중 성지방, 저밀도 지단백 콜레스테롤, 고밀도 지단백 콜레스테롤에서도 상 호작용효과는 나타나지 않았다. 최근 중년여성 20명을 대상으로 1 일 50 분, 주 3 회, 8 주 간 캐딜락, 리포머, 체어와 바렐 등의 기구 필라테스를 실시한 연구에서도 본 연구와 유사하게 체중과 체지방률에 미치는 효과 는 없었다고 보고하고 있다(An \& Seo, 2021). 그러나, 중년 여성을 대상 으로 매트 필라테스 운동을 1일 50분, 주 3회, 8주 간 실시한 연구에서 도 체지방률의 감소효과를 보고하고 있으며(Hyun et al., 2018), 비만 여성을 대상으로 매트 필라테스 운동을 1일 50 60분, 주 3회, 12주 간 실시한 연구에서도 굴루코스, 인슐린, HOMA 지수와 함께 체지방률의 감소효과가 보고되고 있다(Kim et al., 2017). 또한, 필라테스 참여가 여 성의 신체조성과 대사질환관련 혈액지표에 미치는 효과를 분석하기 위 해 국내에 발표된 38편의 논문을 메타분석한 연구에서도 체지방률이 통 계적으로 유의하게 감소되었다고 보고(Oh, 2019)하고 있는 것처럼 필 라테스는 체지방 개선 효과가 있을 것으로 추측된다. 또한 장기간의 매 트 필라테스를 비만의 중년여성(Kim, 2017; Hashemi et al., 2015), 고
령 여성(Kim et al., 2011), 고혈압 노인 여성에게 적용한 결과 혈중지질 (총콜레스테롤, 중성지방, 저밀도 지단백 콜레스테롤, 고밀도 지단백 콜 레스테롤)의 개선에 긍정적인 영향을 나타냈다고 보고되고 있다. 즉, 장 기간의 매트 필라테스의 경우 체지방과 함께 지질대사 개선에 효과가 있 는 것과 대조적으로 기구 필라테스의 경우 근력 위주의 운동효과로 인하 여 근 기능은 개선되나 체지방 및 지질대사 개선 효과는 미비할 가능성 이 있다. 따라서 체지방 개선을 목표로 하여 기구 필라테스를 적용할 경 우 체지방을 연소시킬 수 있는 유산소 운동을 포함 하는 등 보완이 필요 할 것으로 판단된다.

국내 필라테스 관련 연구 313 편의 연구과제 및 연구동향을 분석한 연 구에 의하면 운동생리학 분야(199편, $49.4 \%)$ 와 스포츠심리학 분야(185 편, $45.9 \%)$ 이었으며, 연구주제는 신체조성(49편, $12.1 \%$ ), 건강관련체력 (38편, 9.5\%), 내분비계 35(8.7\%)순이었다고 한다(Choi \& Lee, 2017). 어쩌면 양적으로는 부족하지 않다고 말할 수 있으나, 아직 질적으로 충 분하다고까지 말할 수 없다. 필라테스 연구의 질적 향상을 위하여 운동 강도 및 운동 시간, 빈도 등을 표준화하고, 필라테스 형태별로 비교하는 등의 노력이 필요할 것이다.

또한, 2019체육백서(MCST, 2021)에 의하면 체육활동 참여 종목 순 위에 요가, 필라테스, 태보가 매년 증가하여 2019년에는 5위에 올랐다 고 하는 것처럼 필라테스는 국민체육활동의 하나로 인정받고 있다. 그 러나 필라테스가 건강에 미치는 효과에 대한 과학적 근거는 아직 미약 한 실정이다. 본 연구가 장기간의 기구 필라테스운동은 근육량에 독립 하여 근기능을 발달시킬 수 있다는 하나의 근거가 될 수 있다고 생각된 다. 한편 기구 필라테스 운동 효과를 명백히 하기 위해서 매트 필라테스 집단과 직접 비교할 필요성이 있다. 이를 위한 추가 연구가 필요할 것으 로 사료된다.

\section{결론 및 제언}

본 연구에서는 여대생 24 명을 대상으로 1 일 60 분, 주 3 회, 12 주 간의 스 프링보드 기구 필라테스 운동 부하 실험을 실시하여 장기간의 기구 필 라테스 운동이 근기능과 신체조성에 미치는 효과를 검토하였다. 그 결 과 우측 무릎관절 및 좌·우측 팔꿈치관절 폄근의 등속성 최대 근력 $\left(60^{\circ}\right.$ $/ \mathrm{sec}$ )과 좌측 무릎 폄근 및 우측 팔꿈치폄근과 굽힘근의 등속성 최대 근 지구력 $(180 \% \mathrm{sec})$ 이 유의하게 증가 하는 것이 밝혀졌다. 그러나 전신 및 몸통, 팔, 다리의 근육량에서는 유의한 차이는 나타나지 않았으며, 혈중 근육 성장인자인 성장호르몬과 인슐린 유사 성장인자-I, 25(OH) Vitamin D에서도 유의한 차이 없었다. 혈중 크레아틴 키나제(CK)는 유 의하게 증가하였다. 체중을 포함하여 체지방량 및 체지방률에도 영향을 미치지 못하였으며, 혈중 총콜레스테롤 및 중성지방, 저밀도 지단백 콜 레스테롤, 고밀도 지단백 콜레스테롤에도 영향을 미치지 못했다. 이들 결과로부터 장기간의 기구 필라테스 운동은 근육량을 개선시키지 못하 지만 근기능을 개선시킬 가능성이 시사됐다. 


\section{참고문헌}

An, S. G., \& Seo, Y. H. (2021). Effect of Instrumental Pilates Exercise on Boby Composition and Health Fitness of Middle-aged Women. J. Converg. Sports. Exerc. Sci, 19(1), 65-70.

Anderson, B. D., \& Spector, A. (2005). Introduction to Pilates-Based Rehabilitation. Orthopaedic Physical Therapy Clinics of North America, 9(3), 395-410.

Choi, B. H., \& Kim, C. H. (2006). Pilates Mat Exercises on Low Back Pain, Lumbar Muscular Strength of Elderly, Pain Scale and Body Composition. Korea sport research, 17(5), 633-642.

Choi, J. A., \& Lee, Y. O. (2017). A Plan to Vitalize Sports Instructor System in Elementary School. The Korean Journal of Sport, 15(1), 337-346

Eyal L. (2010). The myth of core stability. Journal of Bodywork and Movement Therapies, 14(1), 84-98.

Fitt, S., Sturman, J., McClain-Smith, S. (1993). Effects of Pilates based conditioning on strength, alignment, and range of motion in university ballet and modern dance majors. Kinesiology and Medicine for Dance, 16(1), 36-51.

Geweniger, V. (2002). Prevention of back pain with Pilates training:[Finding a Healthy Balance]. Pflege Z, 55(10), 747-749.

Hashemi, A., Taghian, F., Kargar Fard, M. (2015). Effect of Pilates for 8 Weeks on Cortisol and Lipid Profile in Obese Women. Quarterly of the Horizon of Medical Sciences, 20(4), 249-255.

Herrington, L., \& Davies, R. (2005). The influence of Pilates training on the ability to contract the transversus abdominis muscle in asymptomatic individuals. Journal of Bodywork and Movement Therapies, 9(1), 52-57.

Hislop, H. J \& Perrine, J. J. (1967). The isokinetic concept of exercise. Phys Ther, 47(2), 114-117.

Hong, S. M., Yang, J. H., Choi, J. H. (2006). Effects of Pilates Matwork Method on Health-Related Fitness and Muscular Band System in the Middle-Aged Women's. Korean journal of physical education, 45(2), 545-556.

Hwang, Y. J., Pack, G. D., Lim, K. W. (2012). 10 Weeks Pilates Mat Exercise' Effects on Body Composition and Basal Physical Fitness of Female College Students. The Korean Journal of Growth and Development, 20(2), 81-88.

Hwang, Y. Y., Pack, J. H., Lim, K. W. (2016). The effect of 12 weeks of pilates exercise elastic band on maximum muscle strength and balance of female university students. Korean Journal of Sports Science, 25(1), 1235-1244.

Hyun, A. H., \& Cho, J. Y. (2021). Effect of 8 Weeks Un-tact Pilates Home Training on Body Composition, Abdominal Obesity, Pelvic Tilt and Strength, Back Pain in Overweight Women after Childbirth. Exerc Sci, 30(1), 61-69.

Hyun, S. j., Ha, S. M., Kim, J. S., Kim, J. H., KIM, D. Y., Kim, S. J. (2018). Effects of Pilates onEstrogen, Serotonin and Dopamine in Middle-aged Women. Journal of Korean Physical Education Association for Girls and Women, 32(1), 149-163.
Katzmarzyk, P. T., Leon, A. S., Rankinen, T., Gagnon, J., Skinner, J. S., Wilmore, J. H., Bouchard, C. (2001). Changes in blood lipids consequent to aerobic exercise training related to changes in body fatness and aerobic fitness. Metabolism, 50(7), 841-848.

Kim, B. H. (2017). Balance and Pilates Exercise on Obesity Index and Blood Lipid Factor in Obese Middle Aged Women. Korea Sport Society, 15(4), 519-525.

Kim, C. S., Kim, J. Y., Kim, H. J. (2015). 8 Weeks Pilates Exercise Site-specifically Improves Legs and Lumbar Vertebral BMD in Women University Students. Exerc Sci. 24(4), 383-390.

Kim, C. S., Kim, J. Y., Kim, H. J. (2014b). The effects of a single bout pilates exercise on mRNA expression of bone metabolic cytokines in osteopenia women. J Exerc Nutr Biochem, 18(1), 69-78.

Kim, H. J., Kim, J. Y., Kim, C. S. (2014a). The effects of pilates exercise on lipid metabolism and inflammatory cytokines mRNA expression in female undergraduates. $J$ Exerc Nutrition Biochem, 18(3), 267-75.

Kim, N. J., Son, W. I., Lee, B. H. (2009). Effects of Pilates mat exercise and detraining on metabolic hormone and coronary artery disease risk factor in obese middle aged women. Exerc Sci. 18(1), 65-74.

Kim, S. H., Rhyu, H. S., Hong, C. K. (2011). Effects of 12 Weeks Pilates Mat Exercise and Elastic Band Exercise on Blood Lipids and Physical Function Performance in Elderly Women. The Asian Journal of Kinesiology, 13(1), 103-112.

Kim, Y. K., Lee, J. Y., Lee S. H. (2017). Effect of Pilates Exercises on Retinaol-binding protein 4, \% Body fat and HOMA index in obese Women. Official Journal of Korean Society of Dance Science, 34(2), 143-152.

Knapik, J., Wright, M. S., Mawdsley, R. H., Braun, J. M. (1983). Isokinetic isometric and isotonic strength relationship. Arch. Phys Med Rehabil, 65, 77-87.

Kraemer, W. J., Fleck, S.J., Dziados, J.E., Harman, E.A., Marchitelli, L.J., et al. (1993). Changes in hormonal concentrations after different heavy-resistance exercise protocols in women. Journal of Applied Physiology, 75(2), 594-604.

Latey, P. (2002). Updating the principles of the Pilates method-Part 2. Journal of Bodywork and Movement Therapies, 6(2), 94-101.

Lee, H. L., Lee, S. K., Kim, M. K. (2017). The Effects of Pilates for Lumbar Stabilization on the Lumbar Muscle Strength and Muscle Activity of Menopausal Women. Journal of Sport and Leisure Studies, 69, 355-363.

Lee, K. H., Kim, B. W ., Kim, C. H., Kim, S. B. (2006). The Effect of Pilates Mat Exercise in 8 Weeks on Middle-Aged Womens' Body Composition, Lumbar Muscle and Flexibility. Korea sport research, 17(2), 655-662.

Liemohn, W. P., Baumgartner, T. A., Gagnon, L. H. (2005). Measuring core stability. J Strength Cond Res., 19(3), 583-586.

Maryela, O. M., Karen, O., Josilene, S. C., Matheus, L C., Daniel, R. K., Rubens, A. D. S., Jefferson R C. (2010). Electromyographic effect of mat Pilates exercise on the back muscle activity of healthy adult females. J Manipulative Physiol Ther, 33(9), 672-678. 
Menacho, M. O., Obara, K, Conceicao, J. S., Chitolina, M. L., Krantz, D. R., da Silva, R. A., Cardoso, J. R. (2010). Electromyographic effect of mat Pilates exercise on the back muscle activity of healthy adult females. $J$ Manipulative Physiol Ther, 33(9), 672-678.

Ministry of Culture, Sports and Tourism(MCST)(2021). 2019 Sport White Paper. Seoul. Ministry of Culture, Sports and Tourism.

Oh, Y. S. (2019). Effect of Pilates Participation in Women on Body composition and Blood Lipids: Meta-Ananlysis. The Korean Society Of Sports Science, 28(4), 913-926.

Oliveira, L. C., Oliveira, R. G., Oliveira, D. A. (2015). Effects of Pilates on muscle strength, postural balance and quality of life of older adults: a randomized, controlled, clinical trial. $J$ Phys Ther Sci, 27(3), 871-876.

Oliveira, L. C., Pires-Oliveira, D. A., Abucarub, A. C., Oliveira, L.S., Oliveira, R. G. (2016). Pilates increases isokinetic muscular strength of the elbow flexor and extensor muscles of older women: A randomized controlled clinical trial. Journal of Bodywork and Movement Therapies, 3, 1-9.

Oliveira, L. C., Oliveira, R. G., Pires-Oliveira, D. A. (2017). Pilates increases the isokinetic muscular strength of the knee extensors and flexors in elderly women. J Body Mov Ther, 21(4), 815-822.

Park, S. S., \& Lee K. J. (2009). Effects of Participation in Pilates and Dance Sports Exercise on Body Composition, Muscular Strength, Flexibility of University Students Group. Journal of Korean Association of Physical Education and Sport for Girls and Women. 23(1), 49-58.

Park, S. S., Chung, Y. J., Kang, H. K. (2011). Effects of Participation in Pilates on Muscular Strength, Proprioception, and Balance of University Students Group. The Korean Journal of Physical Education, 50(1), 235-242.

Phrompaet, S., Paungmali, A., Pirunsan, U., Sitilertpisan, P. (2011). Effects of pilates training on lumbo-pelvic stability and flexibility. Asian J Sports Med, 2(1), 16-22.

Pilates, J. H., \& Miller, W. J, (1945). Return to life through contrology. Ravenio Books.

Segal, N. A., Hein, J., Basford, J. R. (2004). The effects of Pilates training on flexibility and body composition: an observational study. Archives of Physical Medicine and Rehabilitation, 85(12), 1977-1981.

Sekendiz, B., Altun, O., Korkusuz, F., Akin, S. (2007). Effects of Pilates exercise on trunk strength, endurance and flexibility in sedentary adult females. Journal of Bodywork and Movement Therapies, 11(4), 318-326.

Siler, B. (2000). The Pilates Body. New York, Broadway Books.

Wells, C., Kolt, G. S., Bialocerkowski, A., (2012). Defining Pilates exercise: a systematic review. Complement Ther Med, 20(4), 253262.

Yoon, J. K. (1998). The Effects of Maximal Exercise on Serurm Creatine Kinase and Lactate Dehydrogenase. The Korean Society of Sports Medicine, 16(2), 277-281.
Yoon, S. H., Park, G. H., Yoon, S. W. (2007). Effect of 12 week of Pilates Exercise on Flexibility, Muscular Strength and Body Composition of University Women Students. Korean Journal of Sport Science, 18(1), 1-8. 


\section{2주 간의 기구 필라테스가 근기능 및 신체조성에 미치는 영향}

김효진, 김지연, Zhou Yue-Zhu, 김창선

동덕여자대학교 체육학과

[목적] 본 연구는 장기간의 기구 필라테스 운동이 근기능과 신체조성에 미치는 영향을 살펴보는데 있다.

[방법] 여대생 24명을 대상으로 기구 필라테스 운동집단(Instrumental Pilates Group; IPG, n=12)과 대조집단(Control Group; CG, n=12)으로 나누어 1일 60분, 주 3회, 12주 간의 스프링보드 기구 필라테스 운동 부하를 실시하였다.

[결과] 우측 무릎 및 좌· 우측 팔꿈치 폄근의 등속성 최대 근력 $(60 \% \mathrm{sec})$ 에서 상호작용효과가 나타나( $p<.05 ; p<.01)$ 유의 하게 증가 하였다. 좌측 무릎 폄근 및 우측 팔꿈치 폄근과 굽힘근의 등속성 최대 근지구력 $(180 \% / \mathrm{sec})$ 에서 상호작용효과가 나타나( $p<.05 ; p<.01)$ 유의하게 증가 하였다. 전신 및 몸통, 팔, 다리의 근육량에서는 유의한 상호작용이 없었으며(NS), 혈중 근육 성장인자인 성장호르몬과 인슐린 유사 성장인자-I, 25(OH)Vitamin D에서도 상호작용이 없었다(NS). 혈중 크 레아틴 키나아제(CK)는 유의하게 증가하였다(p<.05). 체중 및 체지방량, 체지방률에도 유의한 상호작용이 없었으며, 혈 중 총콜레스테롤 및 중성지방, 저밀도 지단백 콜레스테롤, 고밀도 지단백 콜레스테롤에도 상호작용이 없었다(NS).

[결론] 본 연구의 결과는 장기간의 기구 필라테스 운동은 근육량을 개선시키지 못하지만 등속성 근기능을 개선시킬 가능 성을 시사한다.

주요어

여대생, 기구 필라테스, 등속성 근력, 근육량, 신체조성 